\title{
"Royal" pediculosis in Renaissance Italy: lice in the mummy of the King of Naples Ferdinand II of Aragon (1467-1496)
}

\author{
Gino Fornaciari ${ }^{1}{ }^{+}$, Valentina Giuffra', Silvia Marinozzi², Malayka Samantha Picchi ${ }^{3}$, \\ Massimo Masetti ${ }^{3}$
}

\begin{abstract}
${ }^{1}$ Department of Oncology, Transplants and Advanced Technologies in Medicine, Division of Paleopathology, History of Medicine and Bioethics ${ }^{3}$ Department of Biology, Laboratory of Entomology, University of Pisa, Via Roma 57, 56126 Pisa, Italy ${ }^{2}$ Department of Experimental Medicine, Section of History of Medicine, University of Rome "La Sapienza", Rome, Italy
\end{abstract}

Pediculosis seems to have afflicted humans since the most ancient times and lice have been found in several ancient human remains. Examination of the head hair and pubic hair of the artificial mummy of Ferdinand II of Aragon (1467-1496), King of Naples, revealed a double infestation with two different species of lice, Pediculus capitis, the head louse, and Pthirus pubis, the pubic louse. The hair samples were also positive for the presence of mercury, probably applied as an anti-pediculosis therapy. This is the first time that these parasites have been found in the hair of a king, demonstrating that even members of the wealthy classes in the Renaissance were subject to louse infestation.

Key words: Pediculus capitis - Pthirus pubis - mercury - Italy - XV century

Louse infestation has probably existed in humans since ancient times. The oldest intact head louse egg was found on a hair from an archaeological site in NorthEastern Brazil and dated to 8000 BC (Araujo et al. 2000); the oldest such finding in the Old World is 9,000 years old, from a cave in Israel (Zias \& Mumcuoglu 1991). The oldest known pubic lice are from the Roman period in Britain (Kenward 2001) and from a 2,000-year-old South American mummy (Rick et al. 2002). These archaeological findings clearly indicate that lice were distributed worldwide (Mumcuoglu 2008).

However, this report regards a unique case of lice on the artificial mummy of a XV century Italian king, demonstrating that even wealthy social classes were subject to louse infestation.

The impressive Sacristy of the Basilica of San Domenico Maggiore in Naples houses 38 wooden sarcophagi containing the bodies of 10 Aragonese princes and other Neapolitan nobles who died in the XV and XVI centuries. The collection includes artificial as well as natural mummies (Fornaciari 1998).

Ferdinand II of Aragon (1467-1496), known as "Ferrandino" (little Ferdinand), was the first son of Alfonso II and Ippolita Maria Sforza. In 1494, he was designated by his father as head of the army against Charles VIII, King of France, but he was defeated in 1495. In the same year, at the age of 28 , he ascended to the throne and, following a military campaign, he re-conquered almost all of the Kingdom of Naples. He married his aunt Giovanna of Aragon, the half-sister of his father Alfonso, and died of malignant tertian malaria a few months later, on October 7, 1496 (Brunelli 1996).

+ Corresponding author: g.fornaciari@med.unipi.it

Received 18 November 2008

Accepted 5 March 2009
The mummy of Ferdinand II was badly preserved. Nevertheless, it was possible to sample some locks of hair and pubic hairs still present on the body.

Stereomicroscopic examination of the hair samples revealed the presence of the terminal part of the leg of an adult head louse (Fig. 1A). The terminal parts of two adult abdomens were also found, with the rounded ends clearly showing that the abdominal fragments belonged to a male louse (Fig. 1B). Seven incomplete nits attached to the hair, and another five fragments of nits not cemented to the hair were also detected and observed by Scanning Electron Microscopy (Fig. 2). The same examination carried out on the pubic hairs of Ferdinand II revealed two attached louse nit fragments.

On the basis of the morphology and distribution of the insect fragments observed, it is possible to infer that the king was affected by a double infestation with two different species of lice, Pediculus capitis, the head louse, and Pthirus pubis, the pubic or crab louse.

Furthermore, the hair samples were submitted to a specific procedure in order to verify the concentration of mercury. The mummy of King Ferdinand II of Aragon tested positive for mercury in the hair, at a concentration of $827 \mathrm{ppm}$. The presence of the metal in the hair washing liquid as well confirmed its possible external application.

The high concentration of mercury can be linked to the pediculosis that affected the king and that has been widespread since antiquity. The books of "Secrets", circulating from the end of the XV century, confirm the use of mercury solutions and ointments for the hair, both for aesthetic and therapeutic purposes, during the era of Ferdinand II (Fioravanti 1561).

Furthermore, Byzantine, Arabic (Avicenna 1608) and medieval (Trotula 1856) authors frequently report the use of mercury in anti-pediculosis therapy and the pharmacological practices and therapies aimed at eliminating or preventing infestation by lice. 

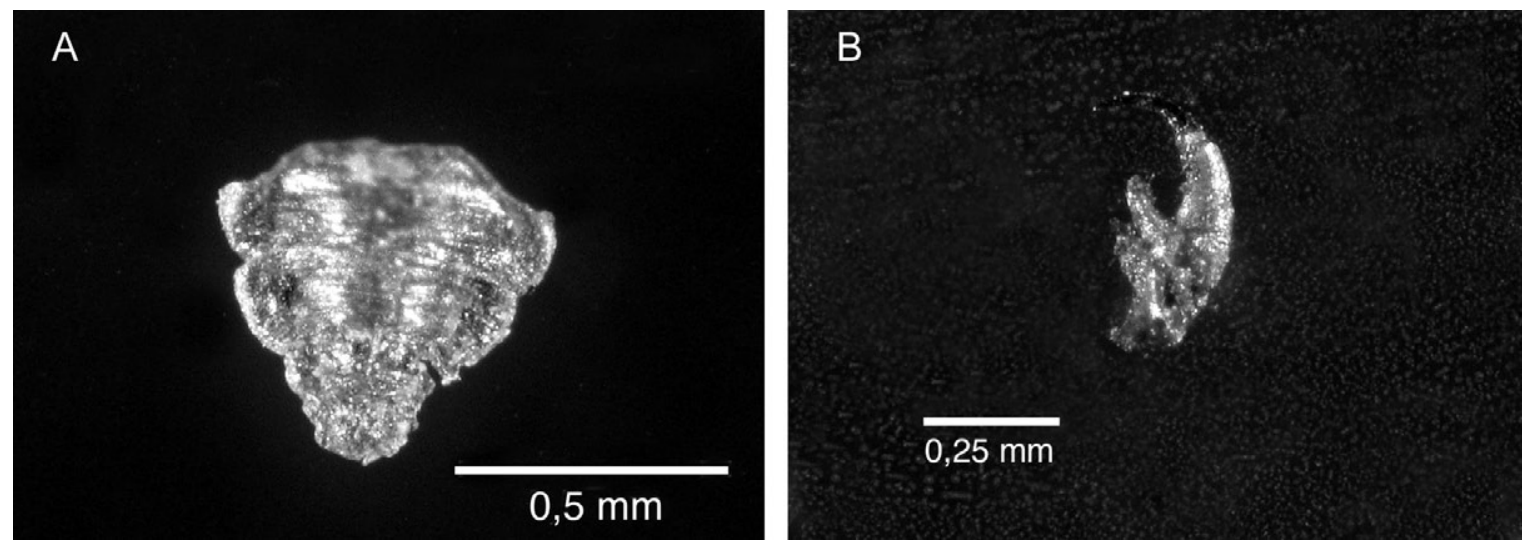

Fig. 1: lice in the hair of Ferdinand II. A: the terminal part of the adult abdomen of a male louse at the stereomicroscope; B: the terminal part of the adult leg of a head louse at the stereomicroscope.

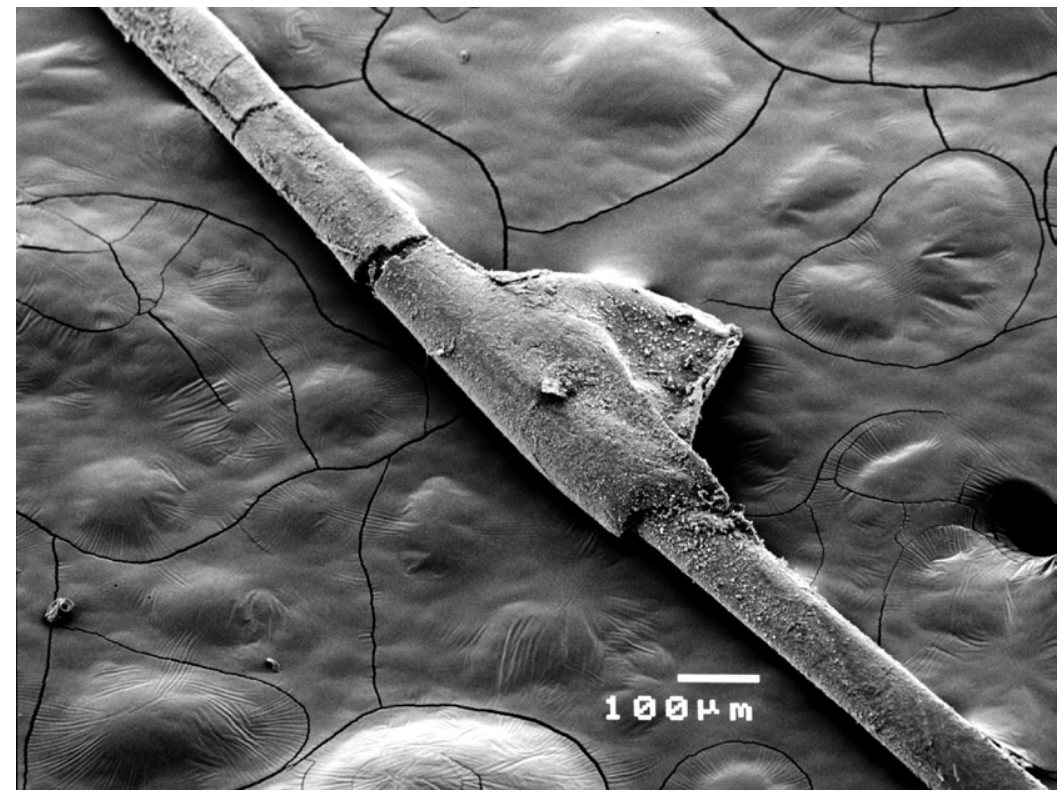

Fig. 2: scanning electron microscopy image of an incomplete nit attached to a hair.

\section{REFERENCES}

Araújo A, Ferreira LF, Guidon N, Maues da Serra Freire N, Reinhard KJ, Dittmar K 2000. Ten thousand years of head lice infection. Parasitol Today 16: 269

Avicenna 1608. Avicennae arabum medico rum principis, ex Gerardo Cremonensis versione..., Apud Iuntas, Venetiis, Vol. I, 437 pp., and Vol. II, $982 \mathrm{pp}$.

Brunelli G 1996. Ferdinando II (Ferrandino) d'Aragona, re di Napoli. In Dizionario biografico degli italiani, Vol. 46, Istituto della Enciclopedia Italiana, Roma, p. 189-194.

Fioravanti L 1561. I capricci medicinali, Lodovico Avanzo, Venetia, $183 \mathrm{pp}$.

Fornaciari G 1998. Italian mummies. In A Cockburn, E Cockburn,
TA Reyman, Mummies, disease \& ancient cultures, Cambridge University Press, Cambridge, p. 271-280.

Kenward H 2001. Pubic lice in Roman and Medieval Britain. Trends Parasitol 17: 167-168.

Mumcuoglu KY 2008. Human lice: Pediculus and Pthirus. In D Raoult, M Drancourt, Paleomicrobiology. Past human infections, Springer, New York, p. 215-222.

Rick FM, Rocha GC, Dittmar K, Coimbra CE, Reinhard K, Bouchet F, Ferreira LF, Araújo A 2002. Crab louse infestation in pre-Columbian America. J Parasitol 88: 1266-1267.

Trotula 1856. De Ornatu Mulierum. In S De Renzi, Collectio Salernitana, Tipografia del Filiatre-Sebezio, Napoli, Vol. IV, p. 30-31.

Zias J, Mumcuoglu KY 1991. Pre-pottery Neolithic B head lice from Nahal Hemar cave. Antiqot 20: 167-168. 